\title{
Core Grid Service
}

National Cancer Institute

\section{Source}

National Cancer Institute. Core Grid Service. NCI Thesaurus. Code C63542.

Services that are needed to maintain the running of a grid, including monitoring and discovery service, security manag ement service (authentication and authorization), identifier naming and resolution service, query and federated query service, and workflow management service. 